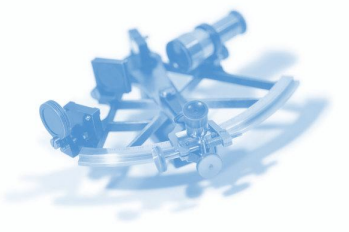

Joanne Broggy* and

George McClelland

National Centre of Excel-

lence in Mathematics and

Science Teaching and

Learning (NCE-MSTL)

University of Limerick

Limerick

Ireland

*Joanne.Broggy@ul.ie

\title{
An investigation to determine the impact of concept mapping on learning in an undergraduate physics course
}

\begin{abstract}
In recent years extensive research has been carried out to evaluate and highlight the declining number of graduates from science related courses. Following this, several initiatives have been designed and implemented throughout the Republic of Ireland to combat the problem of low retention rates in undergraduate science courses and to introduce the use of more effective instructional methodologies that promote the active role of the learner while also encouraging the facilitative role of the teacher. This paper examines Concept Mapping, one such initiative that has been implemented in the University of Limerick over the last two years. The research presented here is part of a large project that aims to explore and evaluate the potential of Concept Mapping as an educational tool in physics education. This paper, however, sets out to specifically answer the following research question: What impact, if any, did Concept Mapping have on four particular aspects of physics learning? The paper examines the effect Concept Mapping had on understanding theory, identifying physics concepts, linking prior and new knowledge and, finally, problem solving.
\end{abstract}

\section{Background}

Overall figures on student completion of university courses in Ireland suggest that an average of $83.2 \%$ of students complete the university course on which they originally enrol $^{1}$. A study on completion ${ }^{2}$ indicates that student completion rates are higher in Ireland than in other European countries. However, within certain areas of study the retention rates decrease. Approximately one-fifth of Science (22.2\%) and Engineering $(19.6 \%)$ students do not complete their courses in Ireland.

Recent research in physics education has recognised the importance of conceptual change in facilitating meaningful learning ${ }^{3,4}$. In tertiary education all science students must study physics as a core subject in their first year. Therefore students who have not specifically enrolled within a physics course will study physics for only one year thus having very little experience with the subject. A majority of these students, identified as non-physics majors, will have not studied physics in secondary level education and as a result are unable to link new to existing knowledge thus preventing the occurrence of conceptual change.

Assessing understanding requires careful observation and thorough analysis. A student's ability to recite definitions of concepts is of limited value as an indicator of conceptual understanding ${ }^{5}$. Definitions should at least be accompanied by examples. To obtain information on the quality of conceptual change taking place within a classroom further questions must be asked and new instruments need to be introduced.

\section{Research Approach}

In order to provide support to university students having difficulty in their course several learning support initiatives have been implemented within universities and postsecondary level institutions. In the past research focused on the activity of the teacher. However it is now increasingly recognised that student activity is central in determining what is learned. It was with this in mind that Concept Mapping was introduced in the University of Limerick.

Concept Mapping is an instructional tool introduced in the early 1970's by Novak and his research team, for the improvement of teaching and meaningful learning ${ }^{6}$. The tool involves students representing their understanding of scientific concepts in a graphical nature whereby concepts are connected creating a hierarchical, branching structure. The underlying technique involved is to tie new knowledge to relevant concepts and propositions already possessed ${ }^{7}$ as it is only when we succeed in relating new 
information to old knowledge that we are able to understand and remember it ${ }^{8}$. Concept maps have been defined as twodimensional, hierarchical, node-linked diagrams that depict those from two courses: biological science education and physical science education. The students' timetable for this module consisted of two one-hour lecture sessions, one twohour lab session and one one-hour tutorial each week.

Training was provided at the beginning of the study to enable students to understand clearly the method of constructing concept maps. The training session was intensive and lasted for fifty minutes. During the training session students got the opportunity to construct maps both in groups and individually. Students then discussed any problems or issues they had with the Concept Mapping tool before the study was commenced and any data gathered. Throughout the period of study students were asked to construct individual maps specific to the module being taught. These Concept Maps also formed part of the delivery of the module where they were used as 'advanced organisers ${ }^{\prime 11}$, allowing the students to identify the relationship between concepts and providing a reference from the beginning of study.

Each student constructed three maps throughout the duration of the 12-week study, a sample of which can be seen in Figures 1(a), 1(b) and 1(c). The level of direction provided varied with the three maps. Direction for the first map consisted of instructions and guidelines to help construct the map and contained a list of seed terms to assist the students in constructing the maps. The second map contained instructions and guidelines with no concepts while the third map contained only the instructions. For each map the

verbal, conceptual, or declarative knowledge in succinct visual or graphic forms ${ }^{9,10}$. The maps provide a representation of knowledge and hence can be used to infer accuracy and depth of knowledge. In order to be effective, instructional concept maps should contain enough important concepts to characterise the subjects that are being represented ${ }^{11}$.

The maps have several components that as a whole represent the student's knowledge on a specific topic. The fundamental component of every concept map is the concept (node). Concepts are defined as "perceived regularities in objects or events that are designated by a sign or symbol"12. Concepts are generally isolated by circles and connected with lines (linking lines). These lines are labelled with "linking phrases", which describe the relationship between the two connected terms. The smallest unit of meaning in the map must contain two concepts and a linking phrase which is then identified as a "proposition". The process of constructing a concept map is a powerful learning strategy that forces the learner to actively think about the relationship between the terms. This makes Concept Mapping especially suited to studying science for the learner who perceives science as simply memorising facts ${ }^{13}$.

\section{Methodology}

The selected first year undergraduate physics module, Sound and Light defined the context of this investigation. The module includes aspects of simple harmonic motion, sound and light waves and physical and geometrical optics. The cohort of students $(\mathrm{N}=84)$ covered a wide variety of abilities from

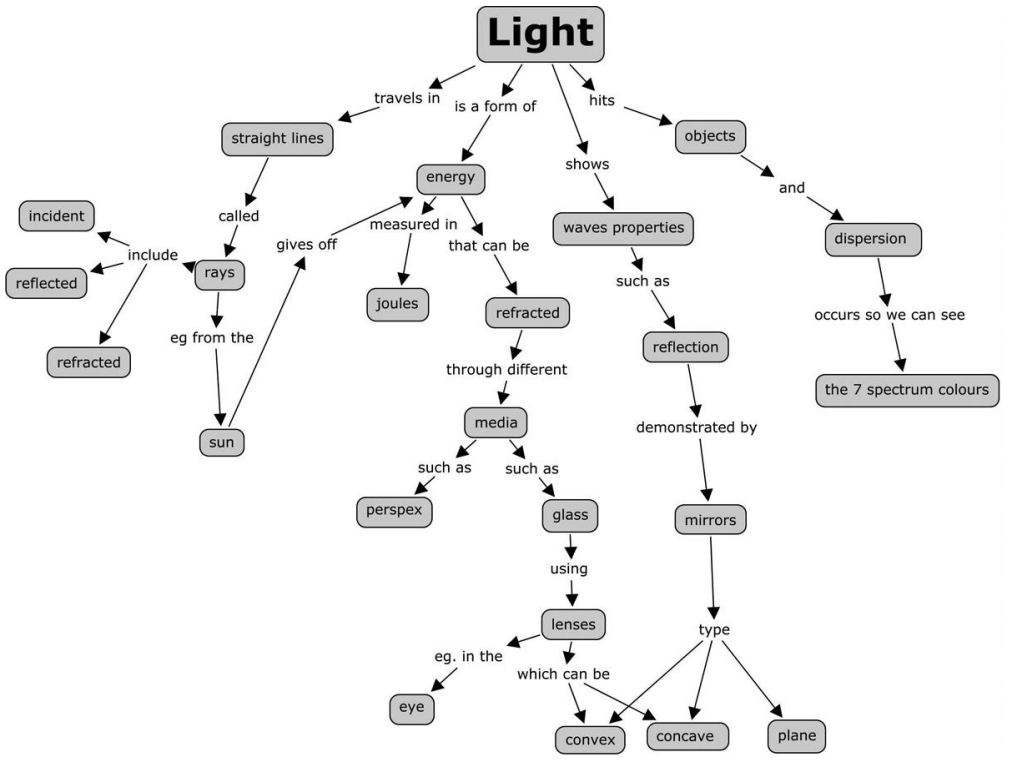

Fig 1 (b): Sample student concept map

students were encouraged to first make a list of all concepts that they believed were important in the topic of light, and then to link these concepts in the form of a map. The students were given the same key concept for all three maps to examine the development of their knowledge over the 12 weeks. The postquestionnaires were self-administered in week 11 after the students had constructed all three maps. 


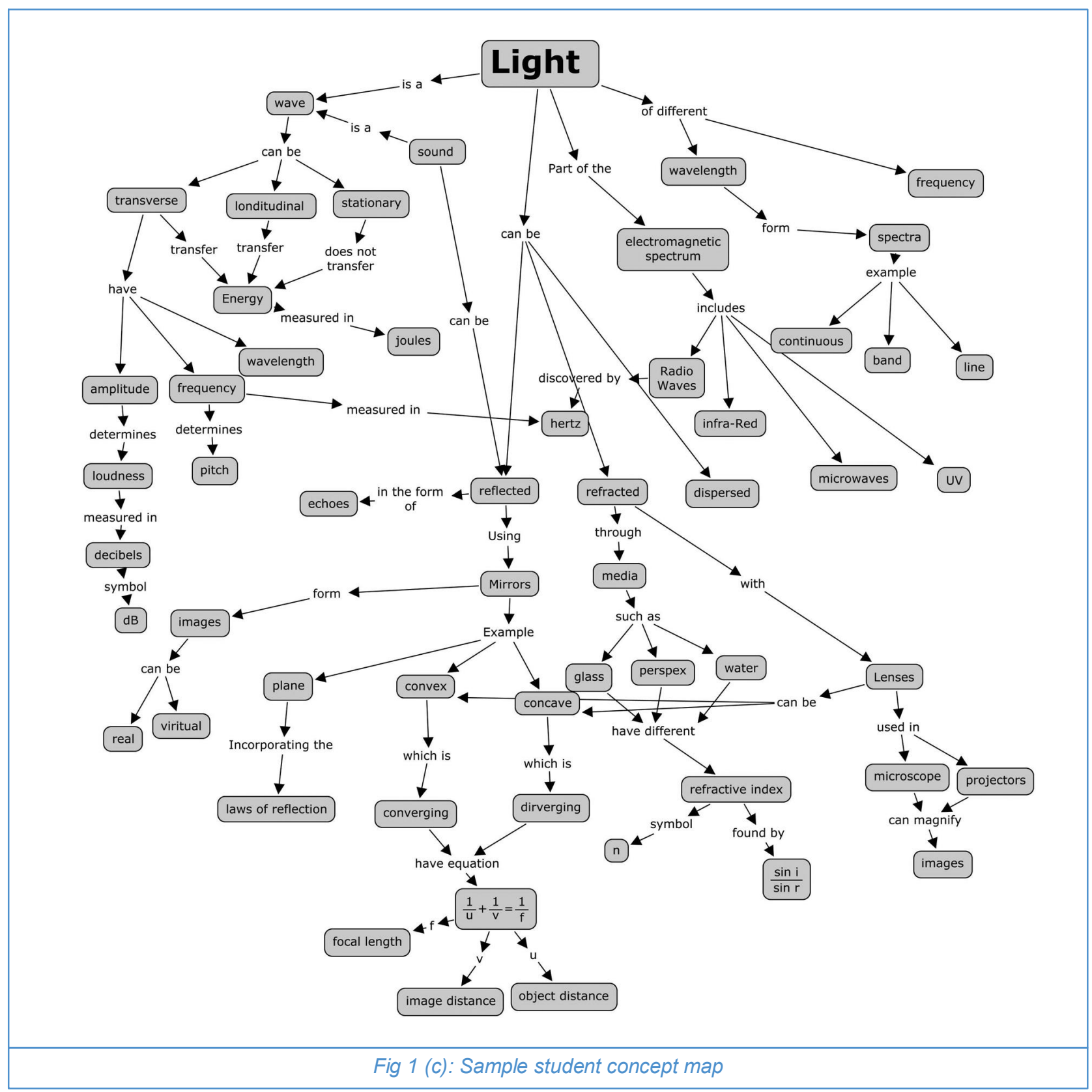

\section{Evaluation}

Analysis of the concept maps was carried out throughout the study and students were given written feedback after the construction of the first map and oral feedback after the second. The written feedback consisted of comments indicating the overall level of the map and highlighting areas on which the students should concentrate, for example the use of linking phrases. The maps were corrected against an expert 'criterion' map which was constructed by the author. All propositions included in the criterion map were specific to the course outline. A 3-point scoring system was developed where one point was attributed to a correct proposition, a half mark for partially correct propositions and zero for a scientifically incorrect one.

Following the 12-week experience with Concept Mapping students rated the effect the tool had on their learning of physics. For the purpose of this study the results focus on four key areas. Students were asked to state, using a Likert Scale, whether they agreed that after their experience with Concept Mapping they were able to:

○ Understand the theory more easily

- Identify physics concepts

- Link prior and new knowledge

- Answers problems more easily.

To determine if the Concept Mapping experience had an effect on students' problem solving ability, the final semester exam grades were analysed and compared against the results of the students' previous physics module, PH4101 Mechanics and Heat. The lecturer for both modules was the same, however the teaching assistant allocated for the timetabled tutorials was not. 


\begin{tabular}{|l|c|c|c|c|c|}
\hline & $\begin{array}{c}\text { Strongly } \\
\text { Agree } \\
(\%)\end{array}$ & $\begin{array}{c}\text { Agree } \\
\text { (\%) }\end{array}$ & $\begin{array}{c}\text { Unsure } \\
\text { (\%) }\end{array}$ & $\begin{array}{c}\text { Disagree } \\
\text { (\%) }\end{array}$ & $\begin{array}{c}\text { Strongly Dis- } \\
\text { agree } \\
\text { (\%) }\end{array}$ \\
\hline $\begin{array}{l}\text { Understand } \\
\text { the theory } \\
\text { more easily }\end{array}$ & 25.4 & 52.4 & 12.7 & 9.5 & 0 \\
\hline $\begin{array}{l}\text { Identify phys- } \\
\text { ics concepts }\end{array}$ & 19.0 & 58.7 & 17.5 & 4.8 & 0 \\
\hline $\begin{array}{l}\text { Link prior to } \\
\text { new con- } \\
\text { cepts }\end{array}$ & 55.6 & 30.2 & 6.3 & 7.9 & 0 \\
\hline $\begin{array}{l}\text { Answer prob- } \\
\text { lems more } \\
\text { easily }\end{array}$ & 12.7 & 44.4 & 23.8 & 17.5 & 1.6 \\
\hline
\end{tabular}

\section{Results}

Following statistical analysis of the student questionnaires the data suggests that the Concept Mapping experience improved the students' learning of physics. (Table 1). Over $50 \%$ of all students agreed or strongly agreed that by constructing concept maps they were better able to understand the theory concepts with existing concepts that an improvement in conceptual understanding can take place.

The questionnaire also set out to evaluate students' perceptions regarding Concept Mapping. The students'

\begin{tabular}{|l|c|c|c|c|c|c|}
\hline Semester & A (\%) & B (\%) & C (\%) & D (\%) & F (\%) & NG (\%) \\
\hline $\begin{array}{c}\text { SEM 1 } \\
\begin{array}{c}\text { Mechanics } \\
\text { and Heat } \\
\text { PH4101 }\end{array}\end{array}$ & 3.3 & 14.6 & 47.2 & 16.8 & 17.9 & 0 \\
\hline$\frac{\text { SEM 2 }}{\text { Light and }}$ \\
$\begin{array}{c}\text { Sound } \\
\text { PH4202 }\end{array}$ & 3.5 & 29.7 & 42.8 & 10.7 & 10.7 & 2.3 \\
\hline
\end{tabular}

Table 2: Students grades in end of semester exams for the module they completed using concept maps ${ }^{*}$ and the previous module taken earlier that year (Note: NG implies No Grade, signifying the student did not sit the exam)

more easily, identify physics concepts, link prior and new knowledge and answer problems more easily. In spite of this, a number of students did 'strongly disagree' with the statement that Concept Mapping had a positive effect on answering problems: $1.6 \%$ of students strongly disagreed that Concept Mapping allowed them to answer problems more easily with a further $17.5 \%$ disagreeing with the statement. The students felt that although they had a better understanding of the theory they found it difficult to manipulate the equations and solve problems. However, when the students' exam results were analysed for both their previous and current physics module there was an improvement of $11 \%$ in the number of students scoring higher than a $\mathrm{C}$ grade (Table 2).

The key point in this study is that over $85 \%$ of students felt that the Concept Mapping tool facilitated the linking of prior to new knowledge. This is imperative for meaningful learning to occur. It is only when students can integrate new science responses were extremely positive regarding the effect the tool had on their attitude towards physics, with $61.9 \%$ agreeing that this improved after their experience with Concept Mapping. Students were then asked if they felt that Concept Mapping was beneficial in a physics classroom. The response to this question was very consistent, with a large proportion of students acknowledging that they felt it is a very valuable revision and study aid. Sample responses include:

"Yes it makes you think about everything you know on a certain topic. It encourages people to generate words first and then connect them"

"Yes it summarises what you have learnt and is a form of revision exercise testing your understanding of a topic" "Yes it allows you to relax and think about the topic rather than rushing to answer a question". 
Conclusions and Implications for Future Directions Data from this study indicates that concept maps can be an effective tool for improving the learning of physics.

Summarising the quantitative and qualitative research we can conclude that concept maps help students integrate prior and new knowledge, understand theory more easily, identify physics concepts and answer problems more easily. It may also be argued that students' grades in the end of semester exams improved following the incorporation of Concept Mapping into the modules as an instructional method.

Concept Mapping is an interesting instructional tool that facilitates meaningful learning and stimulates critical thinking. It assists students in constructing their own understanding and allows them to represent their level of knowledge throughout their course of study. This paper's preliminary findings suggest that the Concept Mapping method employed is effective in providing suitable learning opportunities to undergraduate physics students.

\section{References}

1. Moore, S. (2004) Inter-Universities Retention Network - A submission to the OECD Review Team on the Irish Higher Education System in Irish Universities.

2. Morgan, M., Flanagan, R., and Kellaghan, T. (2000) A study of non-completion in Institute of technology courses. Dublin: Educational Research Centre.

3. Redish, E. F. and Steinberg, R. N. (1999) Teaching Physics: Figuring Out What Works, Physics Today, January, 24-30.

4. Novak, J.D. (2002) Meaningful Learning: The Essential Factor for Conceptual Change in Limited or Inappropriate Propositional Hierarchies Leading to Empowerment of Learners, Science Education, 86(4), 548-571.

5. Savander-Ranne, C. and Kolari, S. (2003) Promoting the Conceptual Understanding of Engineering Students through Visualisation, Global Journal of Engineering Education, 7(2), 189-199.

6. Novak, J.D. and Gowin, D.B. (1984) Learning How to Learn, Cambridge: Cambridge University Press.

7. Austin, L.B. and Shone, B.M. (1995) Using Concept Mapping for Assessment in Physics, Physics Education, 30(1), 41-45.

8. Clifton, C. and Slowiaczek, M.L. (1981) Integrating new information with old knowledge, Memory and Cognition, 9 (2), 142-148.

9. Quinn, H.J., Mintzes, J.J. and Laws, R.A. (2004) Sucessive Concept Mapping, Assessing Understanding in College Science Classes, Journal of College Science Teaching, 33(3), 12-16.

10. Horton, P.B., McConney, A.A., Gallo, M., Woods, A.L., Senn, G.J. and Hamelin, D. (1993) An Investigation of the Effectiveness of Concept Mapping as an Instructional Tool, Science Education, 77(1), 95-111.

11. Schau, C. and Mattern, N. (1997) Use of Map Techniques in Teaching Applied Statistics Courses, The American Statistician, 51(2), 171-175.

12. Novak, J.D. (1991) Clarify with Concept Maps - A tool for students and teachers alike. Science Teacher, 58, 45-49.

13. Dorough, D.K. and Rye, J.A. (1997) Mapping for Understanding-Using Concept Maps as windows to students' minds. Science Teacher, 64(1), 36-41.

\section{Training was provided at the beginning of the study to enable students to understand clearly the method of constructing concept maps.}

